\title{
Evaluation of D2 Attention Levels of Orienteering National Team Athletes Who Are in Education Age
}

\author{
Fatih Bektaş \\ Correspondence: Fatih Bektaş, Trabzon University Faculty of Sport Sciences, Turkey.
}

Received: April 9, 2019

doi:10.11114/jets.v7i6.4204
Online Published: April 24, 2019

URL: https://doi.org/10.11114/jets.v7i6.4204

\begin{abstract}
The aim of this study was to determine the levels of attention in the rest state and post-performance status of the national orienteering team athletes who are in education age with the $\mathrm{d} 2$ attention test. For this purpose, this study was designed with relational screening model from quantitative research approaches. 40 volunteer athletes, 14 of which were female and 26 of them were male, were included in this study group. It was analyzed by Paired Samples t test whether the pre-test and post-test scores which the athletes participating in the study got from the $\mathrm{d} 2$ attention test were different. There was a significant difference among the applications in all scores of the $\mathrm{d} 2$ test $(\mathrm{p}<0.05)$. When the averages of the scores were examined, it was found by performing test repetitions that selective attention ability, sustainability of attention, high motivation and psychomotor speed (TN) most marked material) didn't decrease the stability of psychomotor speed and quality of work performed CP (number of correctly marked d2)] d2 numbers [TN(E1) + (E2)] that were marked incorrectly or weren't marked. As a result; it was observed with $\mathrm{d} 2$ test which is one of the tests used in the field of applied sports psychology to evaluate the visual focusing attention performance of the athletes that the reason of positive differentiation in the attention performances which was obtained after the intensive exercise was intense concentration and the attention levels were high due to the concentration.
\end{abstract}

Keywords: orienteering, D2 attention test, selective attention, continuous attention, performance

\section{Introduction}

\subsection{Introduce the Problem}

It is stated that performance in sports is related to cognitive and perceptual skills as well as with motor and physical ability (Barlow, Woodman, Gorgulu, \& Voyzey, 2016; Schwab \& Memmert, 2012). Sport has been the focus of interest in selective attention. Singer et al., (1993), has stated that the ability to control thought processes and to concentrate on a task for effective performance in sports is a key element. According to Abernethy et al., (2007), continuous attention relates to processing information which coming over a long period of time effectively and efficiently. Caution is measured by wakeful tasks that are highly affected by factors such as fatigue, anxiety, and motivation. Intensified attention can be defined as directing attention to more than one stimulus. In this case, the organism should consciously direct attention to at least two stimuli (Pashler, 1998; Anderson, 1995; Jennings \& Coles 1991). One of the roles that play a key role in more than one task is automation. Automation is the result of that processing some activities causes to decrease zero level of demands of the central capacity as a result of increasing repetition numbers. It has three properties. It does not reduce the performance of the other task, its processes are fast and inevitable (Jonides et al., 1985). Automation is a situation where sportive skills are perfected and transform in mature form over time. In this case, the cognitive focus on the stages of the movement is limited. In sportive branches, it is important to get this feature. One of the sports branches where this feature is important is orienteering.

Orienteering is an adventure sport that involves finding directions in an unconventional region using map and compass, requires a mental and physical capacity (Kjellstrom, 1994), requires the ability to independently think and solve challenges while under pressure and stress, are performed against time and requires continuity between different control points (Larsson, 2002). Orienteering is an extremely healthy sport that activates physics as well as mind. Orienteering is a branch that requires strategy and quick decision making as well as physical power and thinking has an important role in orienteering (Breckle et al., 1989; Douglas, 1990). With the highest performance in the limited area, it can meet the multidimensional expectations from other sports branches, and can even fulfill the physical decision-making and implementation tasks with the results of analytical understanding (Hartmann, 1988). In addition, this sport has a positive effect on development of intelligence and 
attention, coordination and skills development, especially the development of physical, social, psychological and emotional development (Blades \& Spencer, 1989; Renfnew et al., 1993; Andersson, 2001).

Orienteering sport; in increased heart rate with intensive tempo and respiratory environment, to be able to decide with intensive attention in focusing on selective attention in very tired and exhausted situation and achieving the goals, to try finding the target points incorrectly by applying this suitable decision have a positive effect on the psychological development of the athletes. At the end of this study, it was planned to inform about that attention performance could be better after intense exercise. In this respect, it is aimed to show the effect of attention after both resting position and post-performance of the national orienteering team athletes who are in education age with $\mathrm{d} 2$ test which measures attention in this study.

\section{Method}

\subsection{Participant (Subject) Characteristics}

In order to determine the study group, convenience sampling method from purposive sampling was used. The method provides an in-depth study of the situations that are thought to have rich knowledge and the opportunity for the researcher to reach the sample quickly and easily, saving time, energy and resources (Patton, 2014). In line with the principle of volunteering, 40 volunteer athletes who both are in the national team and from Turkey, 14 of which were female and 26 of them were male, were included in this study group. The distribution of statistics on some characteristics of the participants by gender is given in Table 2 .

\subsection{Data Collection Tools}

Include in the Method section information that provides definitions of all primary and secondary outcome measures and covariates, including measures collected but not included in this report. Describe the methods used to collect data (e.g., written questionnaires, interviews, observations) as well as methods used to enhance the quality of the measurements (e.g., the training and reliability of assessors or the use of multiple observations). Provide information on instruments used, including their psychometric and biometric properties and evidence of cultural validity.

Personal Information Form: It was prepared by the researcher to determine the personal characteristics of the study group (gender, age, etc.)

D2 Attention Test: The d2 attention test used in the study was developed by Brickenkamp in 1962. In the following years, the test has undergone several revisions. The aim of the test is to evaluate the ability of continuous attention and visual screening (Spreen \& Strauss, 1998). In the handbook of the test, "the attention and concentration structure" was used as a performance-oriented continuous and focused on selecting a stimulus (Brickenkamp \& Zillmer, 1998). On the front page of the test, there is a section and a research line where the subject's personal information and performance results will be recorded. There is a standard test form on the back page. The test page consists of 14 lines, each with 47 marked letters. Each line has 16 different letters consisting of the letters " $p$ " and "d" with one, two, three and four signs. During the test, the subject must scan the lines to find the two-dotted " $\mathrm{d}$ " letters and draw on them by ignoring the other non-relevant letters. For each line, the subject is given 20 seconds. It can be applied individually or as a group (Brickenkamp \& Zilmer, 1998; Spreen \& Strauss, 1998). The points obtained from the d2 test and their meanings are given below (Brickenkamp \& Zilmer, 1988; Spreen \& Strauss, 1998).

Total Number of Items Processed (TN): It is a quantitative measurement of performance for both related and non-related all processed elements.

Total Error (E): It includes unmarked (E1) and incorrectly marked letters (E2).

Error\% (\% E): A variable that measures the qualitative aspect of performance. It represents the error rate within all items treated. As the error rate decreases, the accuracy of the subject, the nature and caution degree of the work increases.

Total Norm-Error (TN-E): It is the total number of items scanned and minus error points. TN-E is a total performance score. TN-E shows normal distribution, is highly reliable and gives a measure of the relationship between the accuracy and speed of performance. However, TN-E gives more attention to the quantitative side of the performance and less attention to the qualitative side. In exceptional cases, when quantitative and qualitative scores (total score and percentage of error) are excessively high, TN-E tends to overestimate overall performance. Excessive estimates can be avoided by taking into account error points or, alternatively, by examining the concentration performance score recently.

Concentration Performance $(C P)$ : It is obtained by taking away E2 from the number of relevant item marked as true. In contrast to TN-E, CP does not affected from tendencies such as marking all letters or skipping random test sections. It is an excellent index for the accuracy of performance and coordination of speed.

Fluctuation Rate (FR): It is the difference between the line including maximum number of items and the line including 
minimum number of items. This is one of the less reliable measurements of the test. Excessive FR scores may give inconsistency in working speed and may be related to low motivation (Çağlar \& Koruç, 2006).

\subsection{Data Collection}

National orienteering team nominated- athletes are the sample of the study. The test protocol was applied after it was told when the candidate national orienteering team is in resting time in the camp as teams of four. One-to-one intensive performance was applied to the athletes and after performance, individual test protocol was applied to each athlete. The duration between the tests was determined as 4 days.

\subsection{Data Analysis}

Whether the data showed normal distribution was tested by Kolmogorov Smirnov analysis. In this analysis, if the calculated $\mathrm{p}$ value is higher than 0.05 , it can be interpreted that the scores do not show a significant deviation from the normal distribution at this distribution level and it is suitable for this (Büyüköztürk, 2014). In this respect, it was observed that the pre-test and post-test scores of the data collection tool were found to be normal distribution. Thus, the Paired Sample t test was used to determine the difference between the pre-test and post-test scores of the study group.

\section{Results}

The differences between the mean scores belonging pre-exercise and post-exercise of the study group were obtained from $\mathrm{d} 2$ Attention Test were presented in Table 1.

Table 1. Comparison of $\mathrm{d} 2$ test caution parameters before and after exercise

\begin{tabular}{|c|c|c|c|c|c|c|}
\hline \multirow{2}{*}{ d2 Test points } & \multicolumn{2}{|c|}{ Pre Test } & \multicolumn{2}{|c|}{ Post Test } & \multicolumn{2}{|c|}{ t test } \\
\hline & $\mathbf{X}$ & Ss & $\mathbf{x}$ & Ss & $\mathbf{t}$ & $\mathbf{p}$ \\
\hline Total Number of Items Processed (TN) & 511,95 & 79,94 & 590,00 & 60,06 & $-11,028$ &, $00^{*}$ \\
\hline Number of d2 was not marked (E1) & 22,65 & 25,67 & 20,70 & 32,31 & 0,521 & ,60 \\
\hline Number of d2 was marked incorrectly (E2) & 4,10 & 3,47 & 6,70 & 14,58 & 1,113 & ,27 \\
\hline Total error $(\mathrm{E})$ & 26,77 & 25,54 & 27,40 & 42,64 &,- 106 & ,91 \\
\hline Total Norm-Error (TN-E) & 485,17 & 80,25 & 562,60 & 68,14 & $-7,491$ &, $00^{*}$ \\
\hline Concentration performance $(\mathrm{CP})$ & 195,77 & 44,47 & 232,45 & 54,65 & $-4,123$ &, $00^{*}$ \\
\hline Fluctuation Rate (FR) & 18,15 & 9,94 & 10,17 & 5,90 & 5,119 &, $00^{*}$ \\
\hline
\end{tabular}

As seen in Table 1, when pre-test results and posttest attention test results were compared with respect to total number of processed items (TN) scores, significant difference was found $(\mathrm{t}=-11.02, \mathrm{p}<.05)$. The difference between the two measurements is statistically significant in favor of the last test measurement group. It was determined that the number of total markings in the posttest measurement was significantly higher than the pre-test. Any significant differences couldn't found when pre-test and post-test attention test results were compared with respect to the scores "total error (E)" $(t=-0.106, p>.05)$, "the number of $d 2$ that the person hasn't marked" $(E 1)(t=0.521, p>.05)$ and the number of $d 2$ that the person has incorrectly marked $(\mathrm{E} 2)(\mathrm{t}=1.113, \mathrm{p}>.05)$.

When the results of pre-test and post-test attention test was analyzed in table 1 and compared with respect to "Total Norm-Error (TN-E) scores", a significant difference was found $(\mathrm{t}=-7.491, \mathrm{p}<.05)$. The difference between the two measurements is statistically significant in favor of the last test group. In other words, it was determined that the post-exercise defined measurement (post-test) TN-E (total exclusion of errors) scores were significantly higher than pre-exercise defined measurement (pre-test) scores.

When the pre-test and post-test attention test results were examined with respect to "Concentration performance (CP) scores", a significant differences was found $(\mathrm{t}=-4.123, \mathrm{p}<.05)$. The difference between the two measurements is statistically significant in favor of the last test group. In other words, it was determined that the post-exercise defined measurement (post-test) CP (concentration performance) scores were significantly higher than the pre-exercise (pre-test) defined measurement scores.

Finally, when the pre-test and post-test attention test results were analyzed and compared with respect to "Fluctuation Rate (FR) scores", a significant difference was determined $(\mathrm{t}=5.119, \mathrm{p}<.05)$. The difference between the two measurements is statistically significant in favor of the pre-test group. In other words, it is determined the pre-exercise defined measurement (pre-test) FR (fluctuation rate) scores were significantly higher than post-exercise (post-test) defined measurement scores. 
Table 2. Comparison of $\mathrm{d} 2$ test attention parameters belonging pre-exercise according to gender

\begin{tabular}{|c|c|c|c|c|c|c|}
\hline & Gender & $\mathbf{N}$ & $\mathbf{X}$ & Ss & t & $\mathbf{p}$ \\
\hline \multirow{2}{*}{ Total Number of Items Processed (TN) } & Male & 26 & 492,92 & 81,18 & \multirow{2}{*}{$-2,144$} & \multirow{2}{*}{, 039} \\
\hline & Female & 14 & 547,28 & 66,57 & & \\
\hline \multirow{2}{*}{ Number of d2 was not marked (E1) } & Male & 26 & 18,30 & 13,84 & \multirow{2}{*}{$-1,480$} & \multirow{2}{*}{, 147} \\
\hline & Female & 14 & 30,71 & 38,74 & & \\
\hline \multirow{2}{*}{ Number of d2 was marked incorrectly (E2) } & Male & 26 & 4,69 & 3,77 & \multirow{2}{*}{1,491} & \multirow{2}{*}{, 144} \\
\hline & Female & 14 & 3,00 & 2,63 & & \\
\hline \multirow{2}{*}{ Total error $(E)$} & Male & 26 & 23,00 & 12,89 & \multirow{2}{*}{1,284} & \multirow{2}{*}{,207 } \\
\hline & Female & 14 & 33,78 & 39,45 & & \\
\hline \multirow{2}{*}{ Total Norm-Error (TN-E) } & Male & 26 & 469,92 & 78,17 & \multirow{2}{*}{$-1,675$} & \multirow{2}{*}{, 102} \\
\hline & Female & 14 & 513,50 & 79,00 & & \\
\hline \multirow{2}{*}{ Concentration performance (CP) } & Male & 26 & 189,19 & 38,49 & \multirow{2}{*}{$-1,286$} & \multirow{2}{*}{,206 } \\
\hline & Female & 14 & 208,00 & 53,25 & & \\
\hline \multirow{2}{*}{ Fluctuation Rate (FR) } & Male & 26 & 16,53 & 6,74 & \multirow{2}{*}{$-1,414$} & \multirow{2}{*}{, 165} \\
\hline & Female & 14 & 21,14 & 13,94 & & \\
\hline
\end{tabular}

As shown in Table 2, the pre-test attention test results were found significant difference when the "scores of total number of items processed (TN)" were compared by gender $(\mathrm{t}=-2,144, \mathrm{p}<.05)$. The difference between the two measurements is statistically significant in favor of the women.

A significant difference couldn't be found in the pre-test attention test results which were examined in the table when the scores of "Number of d2 was not marked (E1)" )" ( $(\mathrm{t}=-1,480, \mathrm{p}>.05)$, "Number of $\mathrm{d} 2$ was marked incorrectly (E2)" $(\mathrm{t}=1,491, \mathrm{p}>.05)$, “Total error (E)" ( $\mathrm{t}=1,284, \mathrm{p}>.05)$, "Total Norm-Error (TN-E)" ( $\mathrm{t}=-1,675, \mathrm{p}>.05)$, "Concentration performance $(\mathrm{CP})$ " ( $\mathrm{t}=-1,286, \mathrm{p}>.05)$ and "Fluctuation Rate $(\mathrm{FR})$ " ( $\mathrm{t}=-1,414, \mathrm{p}>.05)$ were compared according to gender.

Table 3. Comparison of $\mathrm{d} 2$ test attention parameters belonging post-exercise according to gender

\begin{tabular}{|c|c|c|c|c|c|c|}
\hline & Gender & $\mathbf{N}$ & $\mathbf{X}$ & Ss & $\mathbf{t}$ & $\mathbf{p}$ \\
\hline \multirow{2}{*}{ Total Number of Items Processed (TN) } & Male & 26 & 570,38 & 65,05 & \multirow{2}{*}{$-3,112$} & \multirow{2}{*}{, 00} \\
\hline & Female & 14 & 626,42 & 22,03 & & \\
\hline \multirow{2}{*}{ Number of d2 was not marked (E1) } & Male & 26 & 14,73 & 16,76 & \multirow{2}{*}{$-1,625$} & \multirow{2}{*}{, 11} \\
\hline & Female & 14 & 31,78 & 48,88 & & \\
\hline \multirow{2}{*}{ Number of d2 was marked incorrectly (E2) } & Male & 26 & 4,57 & 3,91 & \multirow{2}{*}{$-1,265$} & \multirow{2}{*}{, 21} \\
\hline & Female & 14 & 10,64 & 24,13 & & \\
\hline \multirow{2}{*}{ Total error $(E)$} & Male & 26 & 19,30 & 16,83 & \multirow{2}{*}{$-1,673$} & \multirow{2}{*}{, 10} \\
\hline & Female & 14 & 42,42 & 67,35 & & \\
\hline \multirow{2}{*}{ Total Norm-Error (TN-E) } & Male & 26 & 551,07 & 66,40 & \multirow{2}{*}{$-1,479$} & \multirow{2}{*}{, 14} \\
\hline & Female & 14 & 584,00 & 68,49 & & \\
\hline \multirow{2}{*}{ Concentration performance $(\mathrm{CP})$} & Male & 26 & 231,30 & 37,78 & \multirow{2}{*}{,- 178} & \multirow{2}{*}{,86 } \\
\hline & Female & 14 & 234,57 & 78,78 & & \\
\hline \multirow{2}{*}{ Fluctuation Rate (FR) } & Male & 26 & 11,80 & 5,87 & \multirow{2}{*}{2,547} & \multirow{2}{*}{, $01^{*}$} \\
\hline & Female & 14 & 7,14 & 4,76 & & \\
\hline
\end{tabular}

As seen in Table 3, a significant difference was be found in the post-test attention test results when the scores of "Total

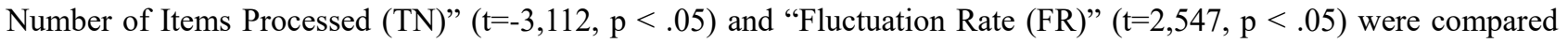
according to gender. The total number of items processed is statistically significant in favor of women, while the fluctuation rate is statistically significant in favor of men.

A significant difference couldn't be found in the post-test attention test results examined in Table 3, when the scores of "Number of d2 was not marked (E1)" ( $\mathrm{t}=-1,625, \mathrm{p}>.05)$, "Number of d2 was marked incorrectly (E2)" ( $\mathrm{t}=-1,265$, $\mathrm{p}>.05)$, "Total error $(\mathrm{E})$ " $(\mathrm{t}=-1,673, \mathrm{p}>.05)$, "Total Norm-Error (TN-E)" $(\mathrm{t}=-1,479, \mathrm{p}>.05)$ and "Concentration performance $(\mathrm{CP})$ " ( $\mathrm{t}=-, 178, \mathrm{p}>.05)$ were compared by gender.

\section{Discussion}

The aim of this study, which is thought to contribute to the field due to limited studies on orienteering sport in the literature (Atakurt, Şahan \& Erman, 2017; Pouya, Demir \& Demirel, 2017; Pulur \& Akcan, 2017), is to determine the level of attention of the athletes of orienteering candidates nationally and after the performance by the D2 test which measures the attention.

At the end of the study, it was determined that the total number of markings was significantly higher than the pre-test measurements in the final test of the orienteering national team athletes. The high number of total marking points shows 
that selective attention ability and sustainability of attention are high. The elevation in TN scores also shows motivation, sustainability of the task, and high psychomotor speed (Brickenkamp \& Zilmer, 1998).

According to the results of covariance, total error before and after the exercise, the number of $\mathrm{d} 2$ which is ineffective and the number of $\mathrm{d} 2$ that the person has marked wrongly have no effect. The excess E1 (type of $\mathrm{d} 2$ that the person has left blank) shows the low level of errors and the insufficient quality of the performance (Brickenkamp \& Zilmer, 1998). One of the elements of attention is autocontrol and self-programming. These elements include controlling an ongoing action, making the necessary adjustments to this action, and then evaluating an action. Autocontrol is the observation of the individual himself when performing an action. Autocontrol is also important in exercise and competitions. E2 (the number of $\mathrm{d} 2$ that a person has flagged wrongly) suggests that the number of such errors is specific learning disability and mental retardation. In addition, carelessness, difficulty in compliance with the directive, visual discrimination also shows the problems (Brickenkamp \& Zilmer, 1998). The absence of any difference before and after this exercise may indicate the continuity of readiness in the national team athletes in orienteering, and show that they are highly skilled in focus and attention.

In the study, TN-E (total number of marking counts-errors) type error pre-test-posttest scores were differentiated in favor of the last test. The high TN-E scores indicate the quality of performance, the balance between psychomotor speed and selective attention (Brickenkamp \& Zilmer, 1998). E1 states the errors about marking skipped errors of items that must be marked during the test. This may also be an indication that the athletes are in a hurry, too excited or too motivated. However, whatever the cause, this situation causes the selective attention of the individual to be low.

In the study, differentiation was determined in favor of the posttest between the $\mathrm{CP}$ (concentration performance) type error pretest-posttest scores. CP scores indicate the stability of the psychomotor speed and the quality of the work performed (Brickenkamp \& Zilmer, 1998). Physical activity is reported to increase cerebral blood flow (Gapin, Labban \& Etnier, 2011). When we look at the chronic effect of cardio sportive activity; Again, it is emphasized that there are positive effects on executive functions, attention and behaviors (Tomporowski et al., 2008; Den Heijer et al., 2017). When these studies are examined, it is seen that it shows parallelism with the current study. In other words, it can be said that the study findings are in parallel with the similar findings in the literature.

In this study, the number of $\mathrm{d} 2$ test (E1), which the person has left blank in the pre-test $\mathrm{d} 2$ test of the national age athletes in the education age, total number of $\mathrm{d} 2$ (E2), the total error (E), total item-error (TN-E), No significant difference was found between the genders in concentration performance $(\mathrm{CP})$ and fluctuation rate $(\mathrm{FR})$ scores. In the final test attention test results, the number of $\mathrm{d} 2$ (E1) left blank by the person, the number of $\mathrm{d} 2$ (E2), the total error (E), the total item-error (TN-E) and concentration performance (CP) scores were compared in terms of gender and no difference was found. Kaymak (2003) concluded that there is no significant difference between female and male students in terms of attention collection level. Attention study was conducted in 18-32 year old students and it was found that there was no significant relationship between attention and gender variable (Zillmer \& Kennedy, 1999). Gordon et al. (1997) found no significant difference between the genders in all of the d2 test scores. Similar to this finding, Zillmer \& Kennedy (1999) 's d2 test in the United States sample to determine the norm values of the pre-study, age 18 to 32 students did not have a significant gender effect. Maxeiner (1987) also found that there was no significant difference between the gender of the $\mathrm{d} 2$ Test in the sports school students. In the German sample, there was no statistically significant difference between the $\mathrm{d} 2$ test scores of male and female subjects (Brickenkamp \& Zillmer 1998). In American children, in a preliminary study to determine the norms of the $\mathrm{d} 2 \mathrm{Test}$ Culbertson \& Sar1 (1997) reported that there was no significant difference between the boys and girls in the d2 Test scores. These findings show similarity to the present study findings.

A significant difference was found in favor of women when compared with the gender of the total number of items (TN) of the pre-test and post-test $\mathrm{d} 2$ Test of the national age athletes. In a study on attention is indicated that, parallel to the findings of this study, girls' attention collection skills are better than males (Borchert, 1998). Toker (1988, 1990) stated that there was a significant difference between the genders in Turkish children sample, female students had higher TN scores in the $\mathrm{d} 2$ Test, but they made more mistakes.

The results of the last attention test of the orienteering national team athletes who are in education age were significant in favor of the men in comparison of the fluctuation rate (FR) scores by gender. Some of the researches in the literature about the attention Helmke \& Renkl (1993), Borchert (1998), say girls are better than men in terms of the ability to collect attention, while Neuhaus (2000) says men are better than girls, although in the literature on attention, in terms of maintaining attention among girls and boys is not different.

In conclusion, according to $\mathrm{d} 2$ pre-test, the high number of total markings (TN) in the final test is that the ability to selective attention after performance, sustainability of attention, high motivation and height in psychomotor speed are a sought after competency in orienteering candidate national team athletes. According to d2 pre-test, the final test equals E1, it was determined that there was no difference in E2-carelessness and problems in visual differentiation with the adequacy of selective attention and performance quality. The fact that TN-E scores differed in favor of the final test is 
important in terms of the quality of performance of the national team athletes and the existence of the balance between psychomotor speed and selective attention. Determination of differentiation between pre-test and post-test scores in terms of CP type is important in terms of showing the stability of the team and the quality of the work done. According to these results, the physical performances of the athletes who are invited to the orienteering candidate national team according to the results of the D2 attention test, are in line with the evidence that the selected athletes are correct.

\section{Acknowledgements}

Collate acknowledgements in a separate section at the end of the article before the references. List here those individuals who provided help during the research (e.g., providing language help, writing assistance or proof reading the article, etc.); Identify grants or other financial support (and the source, if appropriate) for your study.

\section{References}

Abernethy, B., Maxwell, J. P., Masters, R. S. W., Kamp, J. V. D., \& Jackson, R. C. (2007). Handbook of sport psychology, John Wiley. 245-246.

Anderson, J. R. (1995). Cognitive psychology and its implications. Fourth Edition, New York: WH. Freeman and Company.

Andersson, G. (2001). What is orienteering.? Silva Company, SWEDEN.

Atakurt, E., Şahan, A., \& Erman, K. A. (2017). [Examining the effects of orienteering education on attention and memory]. Oryantiring eğitiminin dikkat ve bellek üzerine etkisinin incelenmesi. SPORMETRE Journal of Physical Education and Sport Science, 15(4), 127-134. https://doi.org/10.1501/Sporm_0000000327

Barlow, M., Woodman, T., Gorgulu, R., \& Voyzey, R. (2016). Ironic effects of performance are worse for neurotics. Psychology of Sport and Exercise, 24, 27-37. https://doi.org/10.1016/j.psychsport.2015.12.005

Blades, M., \& Spencer, C. (1989). Children's wayfinding and map using abilities. Scientific Journal of Orienteering, $5(1), 48-60$.

Borchert, J. (1998). Effective trainings programme zur erhöhung schulischer aufmerksamkeit. Ein überblick für lehrkraffte in sonderschulen. Sonderpaedagogischer kongress in Hannover. www.Vdsbundesverband.de/material/kongress98/borchert. htm.1998

Breckle, S. W., Breckle, H., \& Breckle, U. (1989). Vegetation impact by orienteering? A phytosociological long-term study. Scientific Journal of Orienteering, 5, 25-36.

Brickenkamp, R. (1962). Aufmerksamkeits-Belastungs-Test (Test d2). [The d2 test of Attention] (1 edition). Germany, Göttingen: Hogrefe.

Brickenkamp, R., \& Zillmer, E. (1998). The d2 test of attention. Seattle, Washington: Hogrefe \& Huber Publishers. https://doi.org/10.1037/t03299-000

Büyüköztürk, Ş. (2014). [Manual of data analysis for social sciences] Sosyal bilimler için veri analizi el kitabı. Ankara: Pegem A.

Çağlar, E., \& Koruç, Z. (2006). Reliability and validity of d2 test of attention for athletes. Hacettepe J. Sport Sciences, $17(2), 58-80$.

Culbertson, W. C., \& Sari, D. A. (1997). Preliminary normative study of the d2 Test with American children. Arch Clin Neuropsychol, 12(4), 303-304. https://doi.org/10.1093/arclin/12.4.303b

Den Heijer, A. E., Groen, Y., Tucha, L., Fuermaier, A. B. M., Koerts, J., Lange, K. W., Tohome, J., \& Tucha, O. (2017). Sweat it out? The effects of physical exercise on cognition and behaviour in children and ults with ADHD: A systematic literature review. Journal of Neural Transmission, 124(1), 3-26. https://doi.org/10.1007/s00702-016-1593-7

Douglas, E. A. (1990). Impact on flora and fauna of the November Classic 1988, held in the New Forest, Hampshire, England. Scientific Journal of Orienteering, 6(2), 64-82.

Gapin, J. I., Labban, J. D., \& Etnier, J. L. (2011). The effects of physical activity on attention deficit hyperactivity disorder symptoms: The evidence. Preventive Medicine, 52(1), 70-74.

https://doi.org/10.1016/j.ypmed.2011.01.022

Gordon, A. D., Montenegro, L., Culbertson, W., \& Zillmer, E. A. (1997). A normative study of the d2 test with American adults. Arch Clin Neuropsychol, 12(4), 325. https://doi.org/10.1093/arclin/12.4.325

Hartmann, H. (1988). The significance of orienteering in the changing world of sports. Scientific Journal of 
Orienteering. 63-77.

Helmke, A., \& Renkl, A. (1993). Das münchener aufmerksamkeitinventar. Ein instrument zur systematischen verhaltensbeobactung der schüleraufmerksamkeit im unterricht. Diagnostica: Zeitschriff für Psychologische Diagnostic und Differentielle Psychologie, 38, 130-141.

Jennings, R. J., \& Coles, M. G. H. (1991). Handbook of cognitive psychology: Central and automatic nervous system approaches. MA: Cambridge University Press,1991;413-455.

Jonides, J., Naveh-Benjamin, M., \& Palmer, J. (1985). Assessing automaticity. Acta Psychol, 60, $157-171$. https://doi.org/10.1016/0001-6918(85)90053-8

Kaymak, S. (2003). Improving the concentration skill of children attending the second and third classes of a primary school. Unpublished doctoral dissertation. Ankara Üniversiy social Sciences Institute, Ankara.

Kjellstrom, B. (1994). Be expert with map and compass: The complete orienteering handbook. New York third edition: Collier Books.

Larsson, P., Burlin, L., Jakobsson, E., \& Henriksson-Larsen, K. (2002). Analysis of performance in orienteering with treadmill tests and physiological field tests using a differential global positioning system. J Sports Sci, 20(7), 529-535. https://doi.org/10.1080/026404102760000035

Maxeiner, J. (1987). Concentration and distribution of attention in sport. J Sport Exercise Psy, 18, 247-255

Neuhaus, C. (2000). Der hyperactive jugendliche: Erwachsen werden mit ADS. Urania, Ravensburger:

Pashler, H. E. (1998). The Psychology of attention. 2. Edition, London: A Bradford Book, The MIT Press. https://doi.org/10.7551/mitpress/5677.001.0001

Patton, M. Q. (2014). [Qualitative research and evaluation methods] Nitel araştırma ve değerlendirme yöntemleri. Ankara: Pegem Pub.

Pouya, S., Demir, S., \& Demirel, Ö. (2017). [Orienteering games for children with disabilities] Engelli çocuklara yönelik oryantiring oyunları. Kastamonu Üniversity Journal of Forest Faculty, 17(4), 608-618. https://doi.org/10.17475/kastorman.369080

Pulur, A., \& Akcan, İ. O. (2017). [The relationship between visual reaction times and decision making styles of elite orienteering athletes] Elit Oryantiring sporcularının görsel reaksiyon süreleri ile karar verme stilleri arasındaki ilişki. Jornal of Gaziantep University Sport Science, 2(1), 53-61.

Renfnew, T., Mcne1l, C., \& Palmer, P. (1993). Orienteering for the young-guidelines. Sollentuna-Sweden: IOF.

Schwab, S., \& Memmert, D. (2012). The impact of a sports vision training program in youth field hockey players. Journal of Sports Science and Medicine, 11(4), 624-631.

Singer, R. N., Cauraugh, J. H., Tennant, L. K., Murphey, M., Chen, D., \& Lidor, R. (1991). Attention and distractors: Considerations for enhsncing sport performances. International Journal of Sport Psychology, 22, 95-114.

Spreen, O., \& Strauss, E. (1998). A Compendium of neuropsychological tests: administration, norms and commentary: administration, norms and commentary. (2th edition). New York: Oxford University Press.

Toker, M. Z. (1988). Standardization of the visual attention test d2 on a Turkish sample. Unpublished Master's Thesis. Bogazici University. Social Sciences Institute, İstanbul

Toker, M. Z. (1990). [Adaptation of D2 attention test] D2 dikkat testinin uyarlama çalışması. V. National Psychology Congress. İzmir: Special Issue of Psychology-Seminar Journal, 8, 627-635.

Tomporowski, P. D., Davis, C. L., Miller, P. H., \& Naglieri, J. A. (2008). Exercise and children's intelligence, cognition, and academic achievement. Educ. Psychol. Rev., 20(2), 111-131. https://doi.org/10.1007/s10648-007-9057-0

Zillmer, E. A., \& Kennedy, C. H. (1999). Preliminary United States norms fort he d2test of Attention, Archives of Clinical Neuropsychology, 14(8), 727-728. https://doi.org/10.1016/S0887-6177(99)80212-1

\section{Copyrights}

Copyright for this article is retained by the author(s), with first publication rights granted to the journal.

This is an open-access article distributed under the terms and conditions of the Creative Commons Attribution license which permits unrestricted use, distribution, and reproduction in any medium, provided the original work is properly cited. 